Archive for

Organic Chemistry

Arkivoc 2017, part v, 117-128

\title{
Synthesis of Fréchet-type poly(aryl ether) dendrimers with allyl end groups: comparative convergent and divergent approaches
}

Nancy E. Magaña-Vergara, ${ }^{a *}$ Delia Soto-Castro, ${ }^{\text {b* }}$ Hugo Vazquez-Lima, ${ }^{c}$ Rebeca Yépez, ${ }^{d}$ and Rosa Santillan ${ }^{d}$

${ }^{a}$ Facultad de Ciencias Químicas, Universidad de Colima, km 9 Carretera Colima-Coquimatlán, Colima 28400, México

${ }^{b}$ Conacyt-Instituto Politécnico Nacional, CIIDIR Unidad Oaxaca, Hornos 1003, Santa Cruz, Xoxocotlán, Oaxaca, C.P. 771230, México

' Unidad Cuajimalpa, Departamento de Ciencias Naturales, Universidad Autónoma Metropolitana Cuajimalpa,

Av. Vasco de Quiroga 4871, Colonia Santa Fe Cuajimalpa, Delegación Cuajimalpa de Morelos, C.P. 05300, Ciudad de México, México

d Departamento de Química, Centro de Investigación y de Estudios Avanzados del Instituto Politécnico Nacional, Apdo. Postal 14-740, 07000 Ciudad de México, México

Email: nancymv@ucol.mx, dsotoc@ipn.mx

Received 12-20-2016

Accepted 03-03-2017

Published on line $07-23-2017$

\section{Abstract}

The high versatility of allyl groups at the dendrimer periphery makes it important to improve the methodologies to obtain them. Fréchet-type poly(aryl ether) first and second generation dendrimers bearing a conjugated phloroglucinol core with 6 or 12 peripheral allyl groups have been synthesized by convergent and divergent approaches. By the divergent approach the dendrimers were obtained in higher yields and product purification was easier. Steric hindrance proved not to be the key factor in achieving higher yields in the divergent approach; MM and DFT analysis corroborate that electronic effects on the alkoxide play a key role.
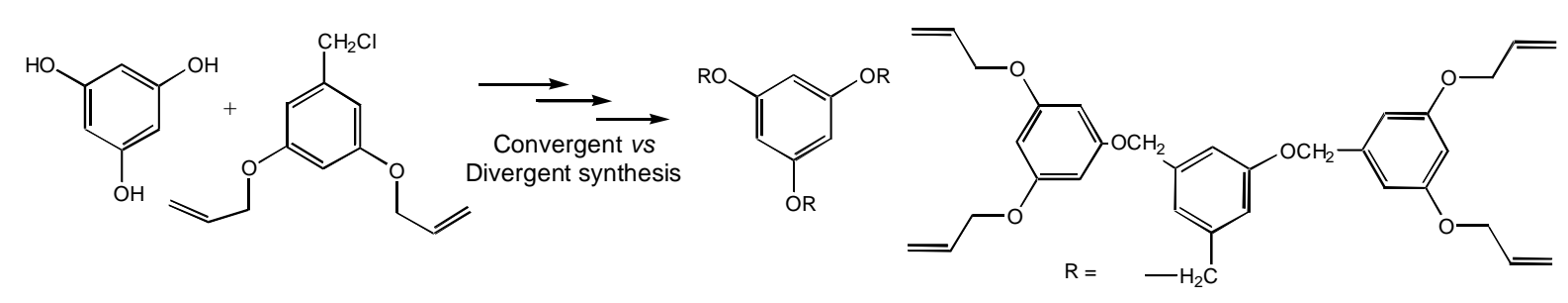

Keywords: Fréchet dendrimer, convergent synthesis, divergent synthesis, molecular mechanics 


\section{Introduction}

In a recent communication ${ }^{1}$ our group reported the synthesis of Fréchet-type poly(aryl ether) dendrimers that incorporate the 1,3,5-triphenylbenzene as core molecule and 3,6, 9, or 12 terminal allyl ether groups using a convergent approach. Although in general the yields are good, when the reaction between the dendron of the second generation and 1,3,5-tris-(4-hydroxyphenyl)benzene (THPB) as core is carried out, the yield falls to $53 \%$. Motivated by potential applications of poly(aryl ether) dendrimers with allyl ether end groups such as preparation of cross-linked dendrimeric materials via ring closing metathesis reactions, ${ }^{2-5}$ the advantage of selective removal of the protecting groups with Pd catalysts to provide peripheral hydroxyl groups that can be functionalized with hydrophobic chains to form new supramolecular polymers, ${ }^{6}$ but mainly because these groups are active for hydrosilylation reactions to obtain metallodendrimers with high-boron-content that can be applied in boron neutron capture therapy (BNCT), ${ }^{7}$ we have continued working on the synthesis of dendrimers with allyl ether terminal groups.

In this paper the synthesis of Fréchet-type poly(aryl ether) dendrimers of the first and second generation containing 6 and 12 terminal allyl ether groups is described. The compounds were prepared using phloroglucinol as core and 3,5-diallyloxybenzyl alcohol as branching units. The aim of this study was to establish the best conditions for the synthesis of this type of dendrimer. To this end we explored both convergent and divergent methodologies, finding that the latter approach provides higher yields, probably due to the electronic effects on the transition states that limit the step of the alkoxide attack to the alkyl halide, according to molecular mechanics and DFT calculations.

\section{Results and Discussion}

\section{Synthetic program}

Due to the promising applications of dendrimers with allyl ether end groups as precursors of metallodendrimers, we explored both convergent and divergent methodologies for the preparation of dendrimer $\mathbf{8}$ of second generation with 12 allyl groups using the sequence of reactions shown in Scheme 1. Although both methodologies employ three steps starting from 1, better yields were obtained in the divergent approach.

The convergent route ${ }^{8}$ required the preparation of dendron $\mathbf{3}$ of the second generation which was coupled to the phloroglucinol core 5. Thus, benzyl chloride derivative 1 was prepared as described in the literature ${ }^{3,6,9,10}$ showing spectral data in accordance with the published one. The reaction of 1 with 3,5dihydroxybenzyl alcohol $\mathbf{2}$ in acetone at reflux in the presence of $\mathrm{K}_{2} \mathrm{CO}_{3}$ and catalytic amounts of $\mathrm{Bu}_{4} \mathrm{NF}$ gave 3

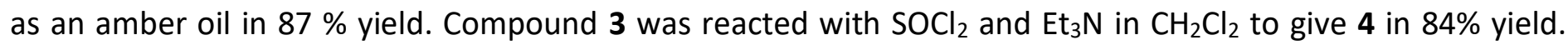
Subsequent reaction of 4 with phloroglucinol 5 in the presence of $\mathrm{K}_{2} \mathrm{CO}_{3}$ and catalytic amounts of $\mathrm{Bu}_{4} \mathrm{NF}$ in DMF at reflux gave 8 as amber oil in $40 \%$ yield (Scheme 1a). In this sequence of reactions, products 3,4 and 8 were purified by flash chromatography on silica gel and the overall yield was $29 \%$. The lower yield of coupling $\mathbf{4}$ and $\mathbf{5}$, compared with the coupling between $\mathbf{4}$ and 1,3,5-tris-(4-hydroxyphenyl)benzene (53\% yield) ${ }^{1}$ could be attributed to the more hindered system when $\mathbf{5}$ is used. 


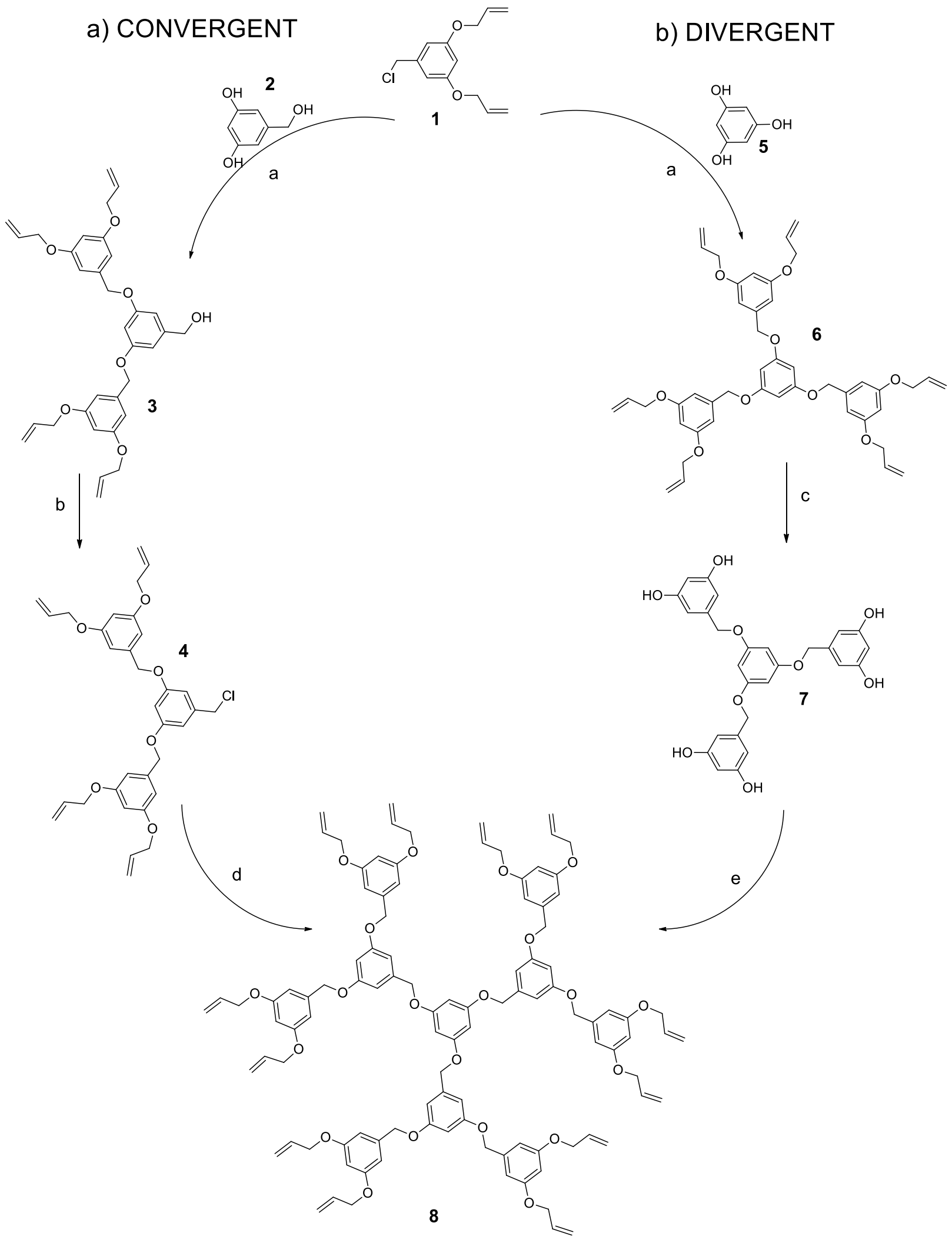

Scheme 1. Synthesis of dendrimer with allyl ether as end groups. a) $\mathrm{K}_{2} \mathrm{CO}_{3}, \mathrm{Bu}_{4} \mathrm{NF}$, acetone. b) $\mathrm{SOCl}_{2}, \mathrm{Et}_{3} \mathrm{~N}$, $\mathrm{CH}_{2} \mathrm{Cl}_{2} \mathrm{c}$ ) $\mathrm{Ph}_{3} \mathrm{P}, \mathrm{Et}_{3} \mathrm{~N} /$ formic acid, $\left.\mathrm{Pd}(\mathrm{OAc})_{2}, \mathrm{EtOH}, \mathrm{d}\right)$ 5, $\left.\mathrm{K}_{2} \mathrm{CO}_{3}, \mathrm{Bu}_{4} \mathrm{NF}, \mathrm{DMF} ; \mathrm{e}\right) 1, \mathrm{~K}_{2} \mathrm{CO}_{3}, \mathrm{Bu}_{4} \mathrm{NF}, \mathrm{DMF} / \mathrm{THF}$. 
The ${ }^{1} \mathrm{H}$ NMR spectra of $\mathbf{6 , 7}$ and 8 are shown in Figure 1. For compound $\mathbf{6}$ (G1) with six allyl groups, the protecting groups appear as a ddd around 6.05 ppm for $\mathrm{H}-9$ while $\mathrm{H}-10 \mathrm{a}$ and $\mathrm{H}-10 \mathrm{~b}$ appear as dd in 5.42 and $5.29 \mathrm{ppm}$, respectively. Additionally, the $\mathrm{dt}$ at $4.52 \mathrm{ppm}$ was assigned to $\mathrm{H}-8$. These characteristic signals of allylic groups disappear upon deprotection evidencing complete reaction. The bottom spectrum corresponds to the second generation dendrimer which shows in addition to the allyl signals, the new aromatic protons at 6.44 and 6.58 ppm. Similarly, $\mathrm{H}-5$ and $\mathrm{H}-7$ in 8 resonate at 6.66 and 6.54 ppm while $\mathrm{H}-10$ and $\mathrm{H}-12$ attributed to the second generation aromatic ring appear at 6.58 and $6.44 \mathrm{ppm}$. Finally, the core proton gives a singlet at $6.25(\mathrm{H}-1) \mathrm{ppm}$ and the methylene protons appear around $5 \mathrm{ppm}$.

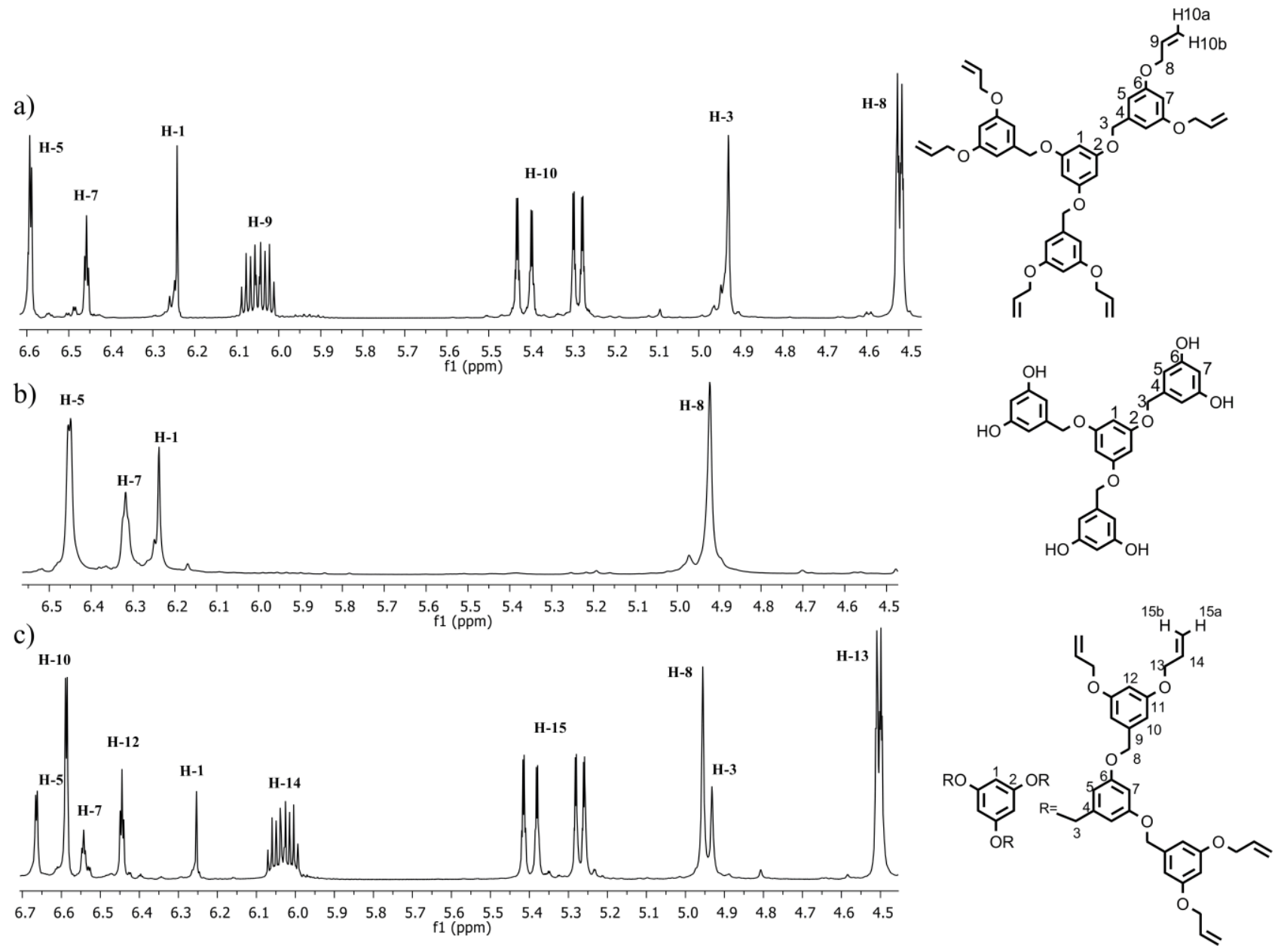

Figure 1. ${ }^{1} \mathrm{H}$ NMR spectra of a) G1 dendrimer 6 with 6 allyl end groups, b) compound 7, and c) G2 dendrimer 8 with 12 allyl groups at the periphery.

The ${ }^{13} \mathrm{C}$ NMR spectrum of 8 shows eight signals attributed to the second generation, one at $70.1\left(\mathrm{CH}_{2} \mathrm{O}-8\right)$, four aromatic carbons at 101.5, 106.2, 160.0 and 139.2 ppm associated to C-9, C-10, C-11 and C-12, respectively, and three for allylic fragment at 68.9 (C-13), 133.1 (C-14) and 117.9 (C-15).

\section{Computational simulations}

In order to determine which of the involved factors are responsible for the lower yield in the convergent methodology compared to the divergent one, some computational simulations were made. 
To account for the dendron steric hindrance in the convergent approach we used two models derived from molecule $\mathbf{5}$. The first one with one dendron $\mathbf{3}$ attached $\mathbf{5 + 3}$ and the second with two dendrons, $\mathbf{5 + 3 + 3 .}$ We used the monodeprotonated phenolate forms with $\mathrm{Bu}_{4} \mathrm{~N}^{+}$as counter-ion in accordance with the reaction conditions. We decided to include three conditions of solvation: vacuum, DMF and water to illustrate the importance of solvation conditions.
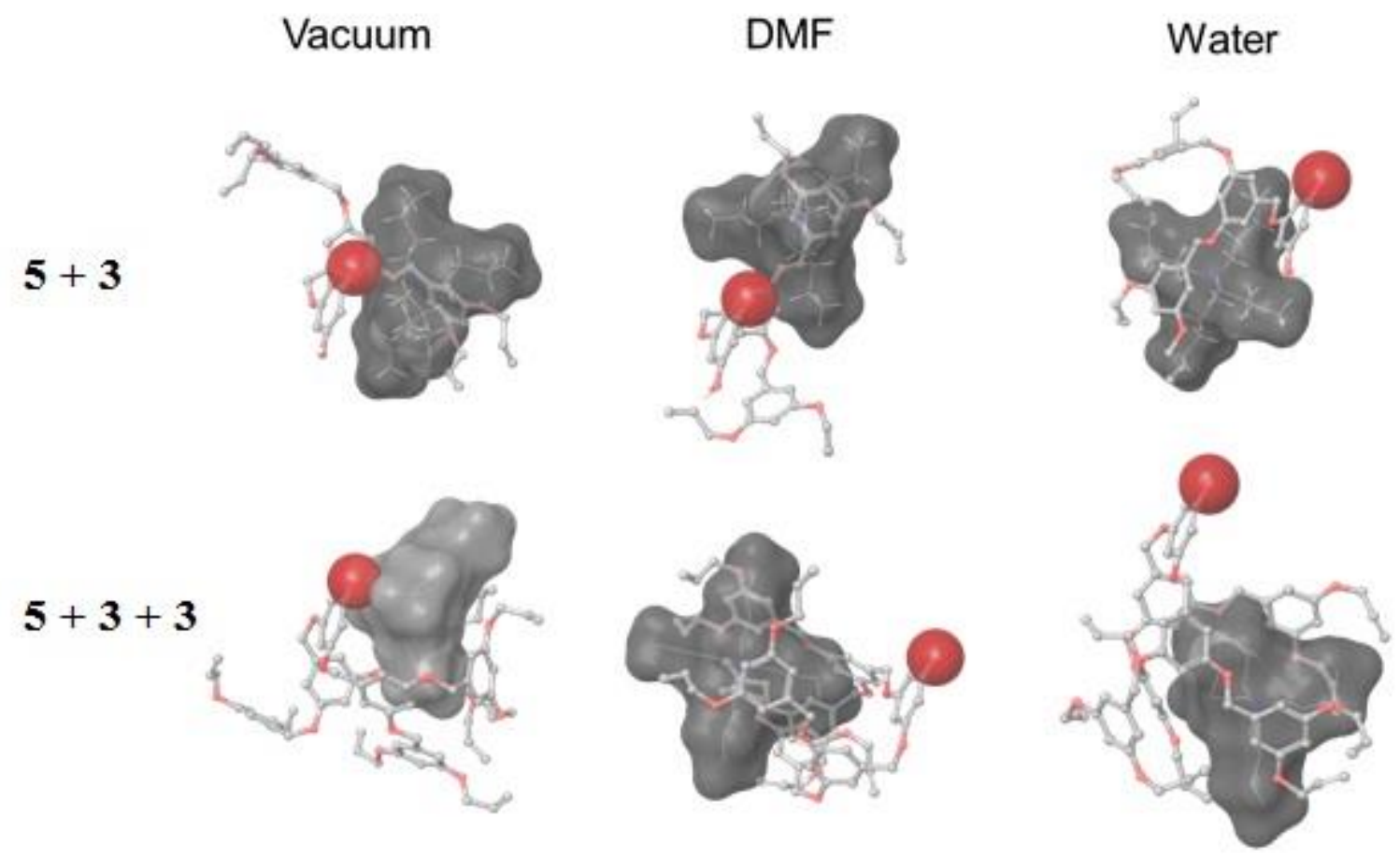

Figure 2. Graphical description of the lowest energy conformation of $(5+3)$ and $(5+3+3)$ models in different solvents. Surfaces: red, anionic oxygen atom; grey, $\mathrm{Bu}_{4} \mathrm{~N}+$ counter cation. Oxygen atoms in red and carbons in grey. Hydrogen atoms omitted for clarity.

From Figure 2 it can be noticed that no significant steric hindrance is present around the reactive anionic oxygen atom in either of the models in DMF. This can be explained because the polar solvent stabilizes the localized charge of the anionic oxygen better than the dendron or the diffuse counter cation. Both of them prefer to interact among themselves rather than to approach the reactive anionic oxygen in DMF. This crucial effect of the solvent is highlighted when the models are calculated in vacuum or water as shown in Table 1. The counter cation approaches significantly close to the reactive anionic oxygen atom in vacuum and it is what we expect in nonpolar solvents. More polar solvents would allow a larger distance between anion and cation. 
Table 1. Distance between the anionic oxygen atom from 5 and nitrogen atom from the $\mathrm{Bu}_{4} \mathrm{~N}^{+}$counteraction

\begin{tabular}{lcc}
\hline Model & Solvent & $\begin{array}{c}\text { Distance }(\AA) \\
\text { OAnion-NCation }\end{array}$ \\
\hline \multirow{2}{*}{$5+3$} & Vacuum & 3.675 \\
& DMF & 4.992 \\
& Water & 15.111 \\
$5+3+3$ & Vacuum & 3.790 \\
& DMF & 10.158 \\
& Water & 11.757 \\
\hline
\end{tabular}

After discarding steric hindrance as the controlling force to explain the higher yield of the divergent protocol, we turned our attention to the electronic effects on the transition states from the limiting step of the alkoxide attack to the alkyl halide. Four small models were selected to represent different steps of the divergent and convergent protocols. They were modeled with DFT B3LYP/TZP/COSMO(DMF). The models are shown in Figure 3 and represent $\mathbf{A}$, addition of the 3rd dendron to $\mathbf{5}$ with two previously attached dendrons; $\mathbf{B}$, addition of the $1^{\text {st }}$ dendron to $\mathbf{5}$; $\mathbf{C}$, addition of a dendron to THPB; $\mathbf{D}$, addition of a molecule $\mathbf{1}$ to a functionalized branch of $\mathbf{7}$. The simulation of $\mathbf{C}$ was chosen because the same reaction was carried out with dendron 4 and THPB, but the yield was higher (53\%). ${ }^{1}$ Therefore, being THPB a core with less steric hindrance, it was expected to provide relevant information of the electronic effect.

The barriers estimated at $153{ }^{\circ} \mathrm{C}$ were A, 25.2; B, 24.6; C, 23.9 and D, 25.1 (all values in $\mathrm{kcal} / \mathrm{mol}$ ). All the transition states (TS) found are within $1.3 \mathrm{kcal} / \mathrm{mol}$, just in the error range of DFT methodology. If we consider only the enthalpy contribution to the energy barrier, the values were A, 6.4; B, 6.7; C, 5.3 and $\mathbf{D}, 4.1$ matching the trend observed experimentally. Although reduced models allow us to get TSs with reasonable quality, the simplification prevents us to access the true entropy of the system, in particular the contribution of the conformational entropy ${ }^{11}$ produced by the many conformers the dendrons can adopt. Obtaining a good approximation to the entropy of the real molecules is not a trivial task and requires extensive conformer to achieve meaningful values of TS. We propose that the part of the dendrons left out from the models play an entropic role in the TSs.

However, these TSs allow us to verify the viability of the molecular mechanics results to avoid clashes between the dendrons in the TSs. In Figure 4, the relaxed dendron $\mathbf{4}$ and the model $\mathbf{5 + 3 + 3}$ were superimposed into the TS A. It can be noticed that the arrangement of the dendrons allows an unhindered interaction in the TS. 

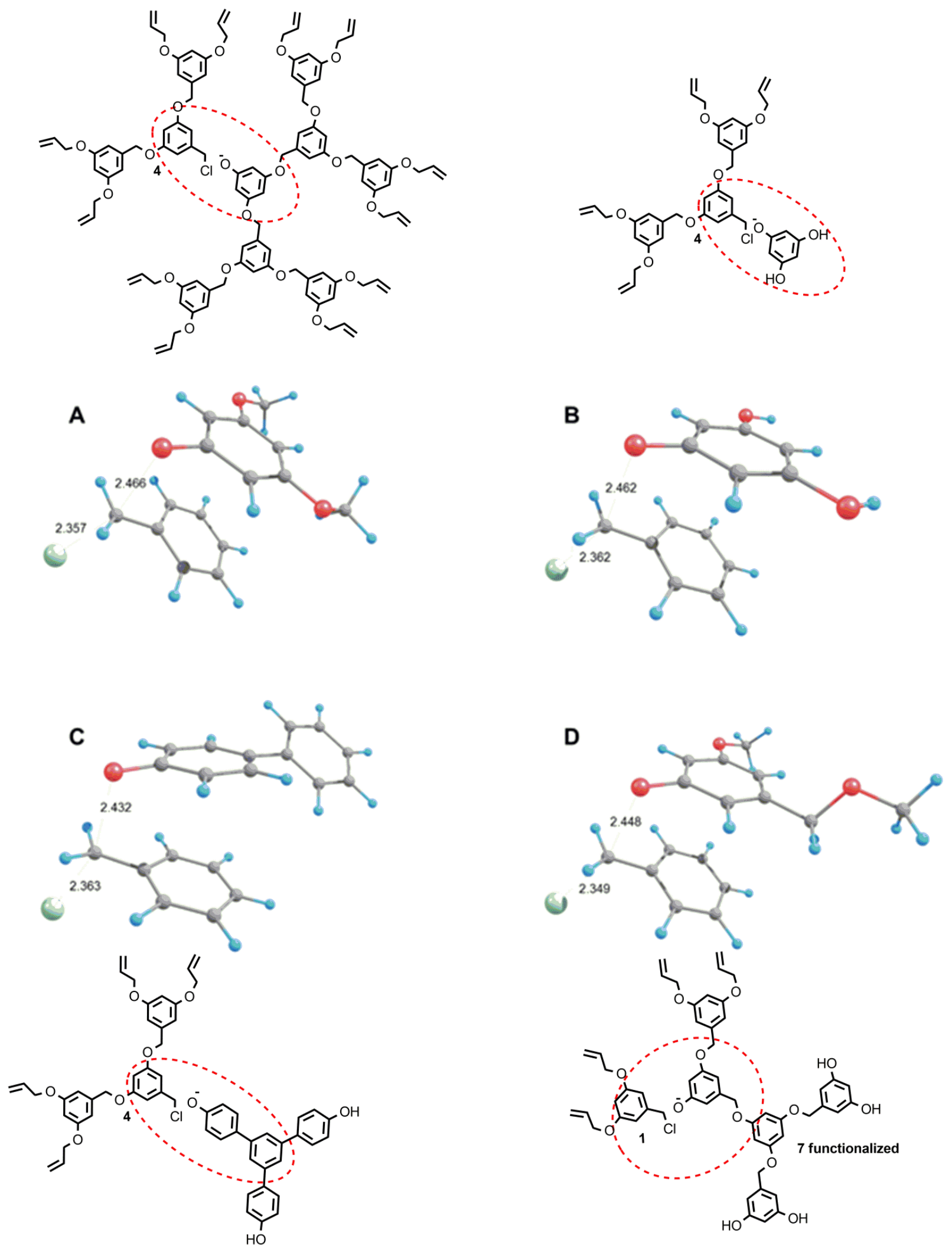

Figure 3. Graphical description of the relevant transition states of divergent and convergent protocols. The models represent reaction of $\mathbf{4}$ with: A, $\mathbf{5}$ with two dendrons; B, 5; C, THPB; D, $\mathbf{7}$ with one dendron. Distances in $\AA$. 

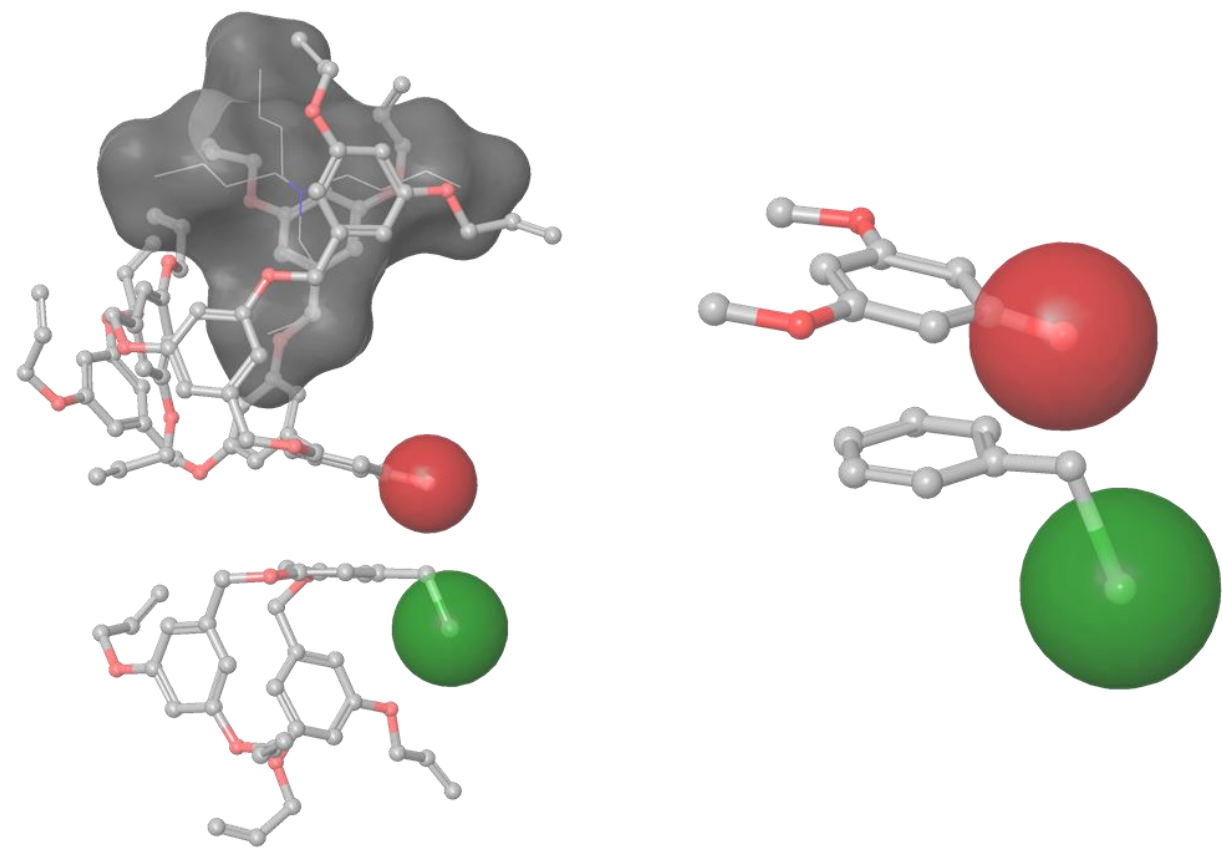

Figure 4. Graphical description of dendron 4 and model $\mathbf{5 + 3 + 3}$ superimposed in the transition state $\mathbf{A}$. Spheres: in red, alkoxide oxygen atom; in green, chloride atom. Surface in grey represent the countercation $\mathrm{Bu}_{4} \mathrm{~N}^{+}$.

\section{Conclusion}

In summary, comparison of convergent and divergent synthetic routes for 1,3,5-tris-\{3,5-bis-[3,5bis(allyloxy)benzyloxy]benzyloxy\}benzene $\mathbf{8}$ showed that in the systems derived from phloroglucinol higher yields are obtained using divergent methodologies. By molecular mechanics the steric hindrance was discarded as the primary influence to explain the higher yield of the divergent protocol, because in the lowest energy conformation the reactive anionic oxygen atom are not hindered. Being the electronic effects on the alkoxide attack to the alkyl halide the limiting step. However, the small models, including the THPB, modeled with DFT B3LYP/TZP/COSMO(DMF) were not enough to corroborate the impact of entropic effects, but the molecular mechanics results to avoid clashes between the dendrons was corroborated.

\section{Experimental Section}

General. ${ }^{1} \mathrm{H}$ and ${ }^{13} \mathrm{C}$ NMR spectra were recorded on a JEOL ECA+500, using $\mathrm{CDCl}_{3}, \mathrm{DMSO}-\mathrm{d}_{6}$, as solvent. Chemical shifts were reported in ppm relative to internal TMS. HRMS were recorded with an Agilent Technologies MS TOF using the ESI(+) technique. IR spectra were recorded determined on a Varian FT-IR Series 640 (ATR). All reagents were commercially available. Column chromatography was carried out with silica gel (70-230 mesh).

\section{Synthesis and characterization}

The branching 1 unit ${ }^{6}$ and the allylic dendron $4^{1}$ were synthesized according to literature procedures. 
3,5-Bis-[3,5-bis(allyloxy)benzyloxy]benzyl alcohol (3). In a round bottom flask were added 3,5dihydroxybenzyl alcohol (1.6 g, $11.4 \mathrm{mmol}), \mathrm{K}_{2} \mathrm{CO}_{3}(9.46 \mathrm{~g}, 6.8 \mathrm{mmol}), \mathrm{Bu} 4 \mathrm{NF}(0.59 \mathrm{~g}, 0.2 \mathrm{mmol})$ in acetone $\left(140 \mathrm{~mL}\right.$ ) and the mixture was heated at $60^{\circ} \mathrm{C}$ followed by the addition of 3,5-diallyloxybenzyl chloride 5 (0.88 $\mathrm{g}, 3.69 \mathrm{mmol})$. The reaction was heated for $24 \mathrm{~h}$, cooled at room temperature and filtered. The filtrate was washed with saturated solution of $\mathrm{NH}_{4} \mathrm{Cl}$ and evaporated under vacuum, furthermore was purified over silica gel to obtain an amber oil $(5.4 \mathrm{~g}, 9.9 \mathrm{mmol})$ in $87 \%$ of yield. The spectral data of 3 was compared with that already published. ${ }^{5,12}$

1,3,5-Tris-[3,5-bis(allyloxy)benzyloxy]benzene (6). To a round bottom flask containing $\mathrm{K}_{2} \mathrm{CO}_{3}(1.53 \mathrm{~g}, 11.1$ $\mathrm{mmol})$ in DMF:THF $(60: 12 \mathrm{~mL})$ as solvent, under nitrogen atmosphere, was added phloroglucinol 5 (0.20 g, $1.23 \mathrm{mmol}$ ) and the mixture was heated at $70{ }^{\circ} \mathrm{C}$ followed by addition of 3,5-diallyloxybenzyl chloride 2 (0.88 $\mathrm{g}, 3.69 \mathrm{mmol})$. The reaction was heated for $24 \mathrm{~h}$, cooled to room temperature and poured over ground ice. The organic layer was extracted with $\mathrm{CH}_{2} \mathrm{Cl}_{2}$ and dried over $\mathrm{Na}_{2} \mathrm{SO}_{4}$ and the solvent was removed under vacuum to obtain a yellow oil $(0.830 \mathrm{~g}, 1.13 \mathrm{mmol})$ in $79 \%$ yield after flash chromatography on silica gel with a mixture of hexane-ethyl acetate (8:2) as eluent. FTIR (ATR) $v_{\max } / \mathrm{cm}^{-1}$ : 3384, 2966, 2932, 1715, 1595, 1446, 1376, 1295, 1242, 1149, 1045, 927, 829, 750, 684. ${ }^{1} \mathrm{H}$ NMR $\left(500 \mathrm{MHz}, \mathrm{CDCl}_{3}\right): \delta_{\mathrm{H}} 6.59(6 \mathrm{H}, \mathrm{d}, \mathrm{J} 2.2 \mathrm{~Hz}, \mathrm{H}-5)$, 6.24(3H, s, H-1), $6.46(3 \mathrm{H}, \mathrm{t}, J 2.2 \mathrm{H}-7), 6.05(6 \mathrm{H}, \mathrm{ddt}, J 17.3,10.6,5.3 \mathrm{~Hz}, \mathrm{H}-9), 5.42(6 \mathrm{H}, \mathrm{dt}, J 17.3,1.3 \mathrm{~Hz}, \mathrm{H}-$ 10a), $5.29(6 \mathrm{H}, \mathrm{dt}, J$ 10.5, $1.3 \mathrm{~Hz}, \mathrm{H}-10 \mathrm{~b}), 4.92(6 \mathrm{H}, \mathrm{s}, \mathrm{H}-3), 4.52(12 \mathrm{H}, \mathrm{dt}, J 5.3 \mathrm{~Hz}, \mathrm{H}-8) .{ }^{13} \mathrm{C} \mathrm{NMR}(125 \mathrm{MHz}$, $\mathrm{CDCl}_{3}$ ): $\delta_{\mathrm{C}} 160.8$ (C-2), 160.2 (C-6), 139.4 (C-4), 133.4 (C-9), 118.4 (C-10), 106.4 (C-5), 101.6 (C-7), 95.1 (C-1), 70.2 (C-3), 69.1 (C-8). MS, m/z (\%): $732\left(\mathrm{M}^{+}\right), 513$ (47), 363 (100), 297 (38), 242 (97), 203 (100), 121 (46), 81 (27), 41 (47).

1,3,5-Tris-[3,5-bis(phenyloxy)benzyloxy]benzene (7). In a round bottom flask were dissolved compound 6 $(0.100 \mathrm{~g}, 1.36 \mathrm{mmol}), \mathrm{PPh}_{3}(0.01 \mathrm{~g}, 0.034 \mathrm{mmol})$ and a mixture of formic acid and triethylamine $(0.41$ $\mathrm{mmol}: 0.41 \mathrm{mmol}$ ) in ethanol as solvent under nitrogen atmosphere, after 30 minutes palladium (II) acetate (1 $\mathrm{mg}, 0.004 \mathrm{mmol}$ ) was added. The reaction mixture was refluxed $24 \mathrm{~h}$, cooled to room temperature and the organic phase was extracted with ethyl acetate and washed with brine, dried over $\mathrm{Na}_{2} \mathrm{SO}_{4}$ and the solvent was removed under vacuum. The title compound was obtained as brown oil $(0.063 \mathrm{~g}, 0.136 \mathrm{mmol})$ and was used in the next step without purification. FTIR (ATR) $v_{\max } / \mathrm{cm}^{-1}: 3322,2930,2162,1596,1434,1370,1144,1047,997$, $919,842,723,682,594 .{ }^{1} \mathrm{H}$ NMR $\left(500 \mathrm{MHz}\right.$, acetone- $\left.\mathrm{d}_{6}\right): \delta_{\mathrm{H}} 6.44(6 \mathrm{H}, \mathrm{brs}, \mathrm{H}-5), 6.31(3 \mathrm{H}, \mathrm{brs}, \mathrm{H}-3), 6.23(3 \mathrm{H}, \mathrm{H}-$ 1), $4.92(6 \mathrm{H}, \mathrm{s}, \mathrm{CH} 2 \mathrm{O}-3) .{ }^{13} \mathrm{C}$ NMR (125 MHz, acetone-d $\left.\mathrm{d}_{6}\right): \delta_{\mathrm{C}} 161.1$ (C-2), 159.0 (C-6), 140.0 (C-4), 106.0 (C-5), 95 (C-1), 71.4 (C-3).

1,3,5-Tris-\{3,5-bis-[3,5-bis(allyloxy)benzyloxy]benzyloxy\}benzene (8). The synthesis of dendrimer 8 was carried out by divergent and convergent approaches.

Method A. Divergent route. In $30 \mathrm{ml}$ of DMF and $6 \mathrm{ml}$ of THF degassed with $\mathrm{N}_{2}$, were suspended $\mathrm{K}_{2} \mathrm{CO}_{3}(0.589$ $\mathrm{g}, 4.26 \mathrm{mmol}$ ) and catalytic amounts of $\mathrm{Bu}_{4} \mathrm{NF}$, followed by addition of compound 7 (0.10g, $\left.0.203 \mathrm{mmol}\right)$. The reaction mixture was heated at $70{ }^{\circ} \mathrm{C}$ and 3,5-diallyloxybenzyl chloride 1 (0.145 g, $\left.0.609 \mathrm{mmol}\right)$ were added continuing the heating for $24 \mathrm{~h}$. Afterwards, the reaction was cooled to room temperature and poured over ground ice and stirred for $1 \mathrm{hr}$. The organic phase was extracted with ethyl acetate and washed with brine, dried over $\mathrm{Na}_{2} \mathrm{SO}_{4}$ and the solvent was removed under vacuum. The crude product was purified by column chromatography eluting with hexane/EtOAc (7:3) to obtain an amber oil $(0.210 \mathrm{~g}, 0.123 \mathrm{mmol})$ in $60.7 \%$ yield.

Method B. Convergent route. Phloroglucinol $(0.118 \mathrm{~g}, 0.72 \mathrm{mmol})$ and 3,5-bis-(3,5bis(allyloxy)benzyloxy)benzyl chloride $4(1.23 \mathrm{~g}, 2.18 \mathrm{mmol})$ were refluxed in DMF for $36 \mathrm{~h}$, in the presence of $\mathrm{K}_{2} \mathrm{CO}_{3}$ and catalytic amounts of $\mathrm{Bu}_{4} \mathrm{NF}$. The organic layer was extracted with $\mathrm{CH}_{2} \mathrm{Cl}_{2}$ and dried over $\mathrm{Na}_{2} \mathrm{SO}_{4}$ and the solvent was removed under vacuum. After a flash chromatography over silica gel with a mixture of 
hexane/ethyl acetate (7:3) as eluent and washed with pentane, the final product was obtained as an amber oil $(0.505 \mathrm{~g}, 0.29 \mathrm{mmol})$ in $40 \%$ yield. FTIR (ATR) $\mathrm{V}_{\max } / \mathrm{cm}^{-1}: 3080,2867,1591,14471142,1042,829,681 .{ }^{1} \mathrm{H}$ NMR $\left(500 \mathrm{MHz}, \mathrm{CDCl}_{3}\right): \delta_{\mathrm{H}} 6.66(6 \mathrm{H}, \mathrm{d}, \mathrm{J} 2.2 \mathrm{~Hz}, \mathrm{H}-5), 6.58(12 \mathrm{H}, \mathrm{d}, J 2.2 \mathrm{~Hz}, \mathrm{H}-10), 6.54(3 \mathrm{H}, \mathrm{t}, J 2.2 \mathrm{~Hz}, \mathrm{H}-7)$, $6.44(6 \mathrm{H}, \mathrm{t}, J 2.2 \mathrm{~Hz}, \mathrm{H}-12), 6.25(3 \mathrm{H}, \mathrm{s}, \mathrm{H}-1), 5.99-6.07(12 \mathrm{H}, \mathrm{m}, \mathrm{H}-14), 5.40(12 \mathrm{H}, \mathrm{dt}, J 17.3,1.5 \mathrm{~Hz}, \mathrm{H}-15 \mathrm{a}), 5.27$ $(12 \mathrm{H}, \mathrm{dt}, J$ 10.5, $1.5 \mathrm{~Hz}, \mathrm{H}-15 \mathrm{~b}), 4.96(12 \mathrm{H}, \mathrm{s}, \mathrm{H}-8), 4.93(6 \mathrm{H}, \mathrm{s}, \mathrm{H}-3), 4.50(24 \mathrm{H}, \mathrm{dt}, J 5.3,1.5 \mathrm{~Hz}, \mathrm{H}-13) .{ }^{13} \mathrm{C} \mathrm{NMR}$ (125 MHz, CDCl 3 ): $\delta_{C} 160.6$ (C-2), 160.1 (C-6), 160.0 (C-11), 139.2 (C-4), 139.1 (C-9), 133.1 (C-14), 117.9 (C-15), 106.5 (C-5), 106.2 (C-10), 101.7 (C-7), 101.45 (C-12), 94.1 (C-1), 70.1 (C-3), 68.9 (C-8, C-13). HRMS m/z: [M+H] $=\mathrm{C}_{105} \mathrm{H}_{109} \mathrm{O}_{21}$, calcd. 1705.74, found 1705.74.

\section{Computational details}

Energy optimizations followed by conformational searches and finalizing with molecular dynamics of the lowest energy conformer were calculated for selected dendrons. Three different solvent conditions were used: vaccum, DMF and water. These calulations were performed with the program Macromodel ${ }^{13}$ using the $^{1}$ force field OPLS $2005,{ }^{14,15}$ and the GB/SA continuum solvation model ${ }^{16}$. Due to the high flexibility of the models we expected many conformers, however the lowest energy conformation of $\mathbf{5 + 3 + 3}$ model in the conformational search was a correct representation of the conformation population. We calculated 122 conformers within $5 \mathrm{kcal} / \mathrm{mol}$ in a conformational search, but the highest RMSD is just to $2.9 \AA$ indicating a similarity in the conformers. Similar values were obtained for $\mathbf{5 + 3}$ model.

DFT calculations were carried out with ADF 2014 program $^{17,18}$ using B3LYP19-23 exchange-correlation functional using the restricted formalism. Scalar relativistic effects were taken into account with the ZORA Hamiltonian ${ }^{24-}$ 28 and ZORA STO-TZP basis set ${ }^{29}$, while Grimme's D3 correction ${ }^{30}$ was used to account for the dispersion effects. All molecules turned out to be minima or transition states according to frequencies calculations. Solvent effects were accounted with COSMO solvation model. ${ }^{31-34}$ All molecular pictures were designed with Maestro. ${ }^{35}$

\section{References}

1. Juárez, P. E. J.; Viñas, C.; Teixidor, F.; Santillan, R.; Farfán, N.; Abreu, A.; Yépez, R.; Núñez, R.

Macromolecules 2010, 43, 150-159.

https://doi.org/10.1021/ma9019575

2. Zimmerman, S. C.; Wendland, M.S.; Rakow, N. A.; Zharov, I.; Suslick, K. S. Nature 2002, 418, 399-403. https://doi.org/10.1038/nature00877

3. Beil, J. B.; Lemcoff, N. G.; Zimmerman, S. C. J. Am. Chem. Soc. 2004, 126, 13576-13577. https://doi.org/10.1021/ja045885j

4. Beil, J. B.; Zimmerman, S. C. Chem. Commun. 2004, 5, 488-489.

https://doi.org/10.1039/b316248f

5. Elmer, S. L.; Zimmerman, S. C. J. Org. Chem. 2004, 69, 7363-7366.

https://doi.org/10.1021/jo049368v

6. Percec, V.; Dulcey, A.; Peterca, M.; Ilies, M.; Miura, Y.; Edlund, U.; Heiney, P. A. Aust. J. Chem. 2005, 58, 472-482.

https://doi.org/10.1071/CH05092 
7. González, C. A.; Ferrer, U. A.; Viñas, C.; Teixidor, F.; Sillanpää, R.; Rodríguez, R. J.; Santillan, R.; Farfán, N.; Núñez, R. Chem. Eur. J. 2013, 19, 6299-6312.

https://doi.org/10.1002/chem.201203771

8. Hawker, C. J.; Frechet, J. M. J. J. Am. Chem. Soc. 1990, 112, 7638-7647.

https://doi.org/10.1021/ja00177a027

9. Yamakawa, Y.; Ueda, M.; Nagahata, R.; Takeuchi, K.; Asai, M. J. Chem. Soc., Perkin Trans.1 1998, 41354139.

https://doi.org/10.1039/a806475j

10. Haba, O.; Haga, K.; Ueda, M. Chem. Mater. 1999, 11, 427-432.

https://doi.org/10.1021/cm980654v

11. Guthrie, J. P. J. Phys. Chem. A 2001, 105, 8495-8499.

https://doi.org/10.1021/jp010321c

12. Dominguez, C. J. G.; Lijanova, I.; Moggio, I.; Arias, E.; Vazquez, G. R. A.; Reyes, V. M. I.; Klimova, T.;

Gutierrez, N. M.; Martínez, G. M. J. Nanosci. Nanotechnol. 2007, 7, 2758-2766.

https://doi.org/10.1166/inn.2007.616

13. Schrödinger Release 2016-3: MacroModel, version 11.3, Schrödinger, LLC, New York, NY, 2016.

14. Kaminski, G. A.; Friesner, R. A.; Tirado, R. J.; Jorgensen, W. J. Phys. Chem. B 2001, 105, 6474-6487. https://doi.org/10.1021/ip003919d

15. Hornak, V.; Abel, R.; Okur, A.; Strockbine, B.; Roitberg, A.; Simmerling, C. Proteins 2006, 65, 712-725. https://doi.org/10.1002/prot.21123

16. Still, W. C.; Tempczyk, A.; Hawley, R. C.; Hendrickson, T. J. Am. Chem. Soc. 1990, 112, 6127-6129. https://doi.org/10.1021/ja00172a038

17. te Velde, G. T.; Bickelhaupt, F. M.; Baerends, E. J.; Fonseca, G. C.; Van Gisbergen, S. J. A.; Snijders, J. G.; Ziegler, T. J. Comput. Chem. 2001, 22, 931-967.

https://doi.org/10.1002/jcc.1056

18. Fonseca, G. C.; Snijders, J. G.; te Velde, G. T.; Baerends, E. J. J. Theor. Chem. Acc. 1998, 99, 391-403.

19. Becke, A. D. Phys. Rev. A 1988, 38, 3098-3100.

https://doi.org/10.1103/PhysRevA.38.3098

20. Lee, C.; Yang, W.; Parr, R. G. Phys. Rev. B 1988, 37, 785-789.

https://doi.org/10.1103/PhysRevB.37.785

21. Russo, T. V.; Martin, R. L.; Hay, P. J. J. Chem. Phys. 1994, 101, 7729-7737.

https://doi.org/10.1063/1.468265

22. Johnson, B. G.; Gill, P. M.; Pople, J. A. Chem. Phys. 1993, 98, 5612-5626.

23. Stephens, P. J.; Devlin, F. J.; Chabalowski, C. F.; Frisch, M. J. J. Phys. Chem. 1994, 98, 11623-11627. https://doi.org/10.1021/j100096a001

24. van Lenthe, E.; van Leeuwen, R.; Baerends, E. J.; Snijders, J.G. Int. J. Quantum Chem. 1996, 57, $281-293$. https://doi.org/10.1002/(SICI)1097-461X199657:3<281::AID-QUA2>3.0.CO;2-U

25. van Lenthe, E.; Snijders, J. G.; Baerends, E. J. J. Chem. Phys. 1996, 105, 6505-6516. https://doi.org/10.1063/1.472460

26. van Lenthe, E.; Snijders, J.G.; Baerends, E. J. J. Chem. Phys. 1994, 101, 9783-9792. https://doi.org/10.1063/1.467943

27. van Lenthe, E.; Ehlers, A.; Baerends, E. J. J. Chem. Phys. 1999, 110, 8943-8953.

https://doi.org/10.1063/1.478813 
28. van Lenthe, E.; Baerends, E. J.; Snijders, J. G. J. Chem. Phys. 1993, 99, 4597-4610. https://doi.org/10.1063/1.466059

29. van Lenthe, E.; Baerends, E. J. J. Comput. Chem. 2003, 24, 1142-1156. https://doi.org/10.1002/icc.10255

30. Grimme, S.; Antony, J.; Ehrlich, S.; Krieg, H. J. Chem. Phys. 2010, 132,154104. https://doi.org/10.1063/1.3382344

31. Pye, C. C.; Ziegler, T. Theor. Chem. Acc. 1999, 101, 396-408. https://doi.org/10.1007/s002140050457

32. Klamt, A.; Jonas, V. J. Chem. Phys. 1996, 105, 9972-9981. https://doi.org/10.1063/1.472829

33. Klamt, A. J. Phys. Chem. 1995, 99, 2224-2235. https://doi.org/10.1021/j100007a062

34. Klamt, A.; Schuurmann, G. J. Chem. Soc., Perkin Trans. 2 1993, 5, 799-805. https://doi.org/10.1039/P29930000799

35. Schrödinger Release 2014-1: Maestro, version 9.7, Schrödinger, LLC, New York, NY, 2014. 